\title{
A multilevel investigation supported by multivariate analysis for tomato product formulation
}

\author{
Fatma Boukid $^{1,2} \cdot$ Elena Curti $^{1} \cdot$ Agoura Diantom $^{3} \cdot$ Eleonora Carini $^{1}$ (1) $\cdot$ Elena Vittadini $^{4}$
}

Received: 26 February 2021 / Revised: 1 June 2021 / Accepted: 5 June 2021 / Published online: 18 June 2021

(c) The Author(s) 2021

\begin{abstract}
Industrial processing of tomato includes its cutting and mincing, thermal treatments, and the addition of ingredients, which might induce changes in physicochemical properties of the final products. In this frame, the impact of texturing/thickening [xanthan gum (X) or potato fiber (F)] on the macroscopic, mesoscopic and molecular properties of tomato double concentrate (TDC) was investigated to determine if $F$ can efficiently substitute $X$, in association with small solutes (sugar and salt) and thermal treatment (cold and hot). At a macroscopic level, multivariate statistics (MANOVA) underlined that color change $(\Delta E)$ was increased by $\mathrm{X}$ and $\mathrm{F}$ addition contrary to heating and the addition of salt and sugar. MANOVA revealed that texture was greatly enhanced through the use of F over X. ${ }^{1} \mathrm{H}$ NMR molecular mobility changes were more controlled by texturing agents $(\mathrm{F}$ and $\mathrm{X})$ than thermal treatment and small solutes. Particularly $\mathrm{F}$ increased the more rigid population indicating stronger interaction with water molecules resulting in shear-thinning flow. However, adding X contributed into the increase of the dynamic and mobile populations. Therefore, F can be a valid "clean label" substitute of X in modulating tomato products properties.
\end{abstract}

Keywords Xanthan $\cdot$ Potato fiber $\cdot$ Salt $\cdot$ Sugar $\cdot$ NMR $\cdot$ Rheology $\cdot$ Color

Eleonora Carini

eleonora.carini@unipr.it

Fatma Boukid

fatma.boukid@irta.cat

Elena Curti

elena.curti@unipr.it

Agoura Diantom

josephagouradiantom@gmail.com

Elena Vittadini

elenagiovanna.vittadini@unicam.it

1 Department of Food and Drug, University of Parma, Parco Area delle Scienze 47/a, 43124 Parma, Italy

2 Institute of Agriculture and Food Research and Technology (IRTA), Food Safety and Functionality Programme, Food Industry Area, Finca Camps i Armet s/n, 17121 Monells, Catalonia, Spain

3 Ecole Supérieure des Techniques Biologiques et Alimentaires, University of Lome, BP 1515 Lome, Togo

4 School of Biosciences and Veterinary Medicine, University of Camerino, Via Gentile III da Varano, 62032 Camerino, Macerata, Italy

\section{Introduction}

Tomato is one of the most marketed vegetables worldwide and holds the fourth position behind potatoes, lettuce, and onions with more than 160 million tons produced annually [1]. Tomato is widely consumed as a fresh product or can be processed in several ways such as sauce, juice, ketchup, pulp, purée, paste and peeled whole tomato [2-5]. The quality of these products is strongly influenced by preprocessing (e.g. variety, agronomic and harvest conditions), processing (e.g. heat and mechanical treatments) and post-processing (e.g. transport and storage) parameters [6-8]. Therefore, to enable the production of a standardized product with desired and stable quality, various ingredients with different purposes (e.g., texturing, flavoring or water binding ingredients) are commonly included in tomato products formulation. Viscosity is one of the most critical quality features for consumer acceptance [9-11]. Texturing agents are indeed commonly used to modulate product' viscosity and its stability during storage, and consequently its sensory characteristics [12]. Hydrocolloids are ingredients usually added to tomato products to increase their viscosity $[1,13,14]$. Xanthan gum $(\mathrm{X})$ is a hydrocolloid widely used due to its ability 
to give high viscosity at low concentrations (at $1 \%$ solids of $1000-4300 \mathrm{mPa} \mathrm{s}$ ) and high solubility both in hot and cold water [15]. However, $\mathrm{X}$ is considered a food additive (E415) according to Regulation (EC) No 1333/2008 [16], and consequently industrials are increasingly looking for "clean label" substitutes in response to consumers' request for natural ingredients [17]. Potato fiber (PF) extracted from potato peel waste was reported to improve the texture and the water binding capacity in the product $[18-20]$. Potato fiber has been recognized with specific physico-chemical and functional properties (e.g. high water-holding capacity and emulsifying) [21, 22]. In a previous work [19], different ingredients (guar, xanthan, carboxy methyl cellulose, locust bean gums, potato fiber, milk, potato and soy proteins) were added to tomato sauce at different levels $(0.5,1$ and $1.5 \%)$ to investigate their effect on its physico-chemical properties. Results showed that the addition of ingredients did not affect water activity, irrespectively of their nature and concentration, except PF that significantly reduced water activity suggesting that $\mathrm{PF}$ had stronger water binding capacity than the other ingredients used. Furthermore, F was tested as a potential texturizing agent to substitute xanthan $(\mathrm{X})$ in tomato pulp, double and triple tomato concentrate at different levels $(1,1.5$ and $2 \%)$ and under two heat treatments [18]. A higher redness was obtained at $2 \%$ (g ingredient $/ 100 \mathrm{~g}$ of product) of $\mathrm{F}$ in double and triple tomato concentrate. $\mathrm{F}$ also showed a stronger effect on apparent viscosity than $\mathrm{X}$ in the case of triple tomato concentrate. In this study, the effect of these texturizing agents was probed also at molecular level (with ${ }^{1} \mathrm{H}$ NMR relaxometry) and it was found that $\mathrm{F}$ reduced proton molecular mobility, in contrast with $\mathrm{X}$. F was therefore suggested as a potential "clean label" substitute for X in tomato-based products.

In tomato products, in addition to texturizing agents, other ingredients find usually space to serve different purposes, including flavor and color improvement, syneresis and water activity control. Salt and sugars can play the role of flavoring agents to enhance the taste and flavor as well as the color of tomato products and, therefore, they are largely used in commercial salsa-condiments. Salt and sugars can both modify water dynamics by importantly reducing water activity thus reducing growth of spoilage and pathogenic microorganisms during storage [23]. Besides, salt can enhance color stability due to the reduction of enzymes activity related to the browning of tomato sauce [12]. The presence of various ingredients in complex formulations of tomato products can affect their end-quality depending on the type/properties of the used ingredient and its mechanism of action.

A full factorial design was designed to study the impact of different levels $(1,1.5$ and $2 \%)$ of $\mathrm{F}$ and $\mathrm{X}$ on the physico-chemical properties of three different tomato products [tomato pulp, double and triple tomato concentrate] processed under different thermal treatments (cold and hot).
Results showed that F can be used as a possible substitute to $\mathrm{X}$ in modulating the physico-chemical tomato products properties [18]. Going forward, the present investigation aims to point out the effect of salt and sugar in association with texturizing agents $(\mathrm{F}$ and $\mathrm{X})$, which are common multifunction ingredients (flavoring, water binding and stabilizing) in tomato products formulation. In this perspective, this work aims to modify the recipe of tomato double concentrate (TDC) to evaluate the effect of substituting $\mathrm{X}$ by $\mathrm{F}$ in association with the addition of different levels of sugar and salt. Salt, sugar and thickening agent ( $\mathrm{X}$ or $\mathrm{F}$ ) were added into TDC and subjected to heat treatment $\left(80^{\circ} \mathrm{C}, 20 \mathrm{~min}\right)$ to reproduce cooking process. The effect of formulation and heat treatment were evaluated using a macroscopic (water activity, moisture content, $\mathrm{pH}$ and color), mesoscopic (rheological properties with rheometer) and molecular (proton mobility with ${ }^{1} \mathrm{H}$ NMR Relaxometry) multilevel approach. Through multivariate statistics, the considered factors (ingredients: X, F, salt, sugar; heat treatment: hot and cold) were thoroughly analyzed to determine their weight on quality changes of the final product.

\section{Materials and methods}

\section{Tomato products' preparation}

The ingredients used in this study were: tomato double concentrate (TDC, Mutti S.p.a., Parma, Italy); xanthan [X, humidity: $\max 13 \%(\mathrm{~g} / 100 \mathrm{~g})$; ashes: $\max 13 \%$; proteins (Nx6.5) max 5\%; fat: $\max 1 \%$ Chimab S.p.a, Campodaresego, Italy], potato fiber [F, moisture $<6.0 \%$, protein $<1.0 \%$, fat $<1.0 \%$, non-dietary fiber carbohydrates $<1.0 \%$, dietary fiber $\sim 92.0 \%$ (soluble fiber $~ 73.0 \%$; insoluble fiber 19.0\%), ashes $2.0 \%$; HI-FOOD S.p.a, Parma, Italy], white refined sugar (Inagra, Reggio Emilia, Italy) and table salt (fine sea salt, Artisale S.p.a., Margherita di Savoia, Italy). All the tomato product used in this study originated from the same industrial production.

Tomato double concentrate (TDC) was mixed with $1 \%$ (g ingredient $/ 100 \mathrm{~g}$ tomato) of texturing agent $(\mathrm{X}$ or $\mathrm{F})$ and two levels [0.5 and $1 \%$ (g ingredient $/ 100 \mathrm{~g}$ tomato)] of stabilizing agents (sugar and salt) at $25^{\circ} \mathrm{C}$ for $2 \mathrm{~min}$ at $500 \mathrm{rpm}$ using a mixer (Bimby ${ }^{\circledR}$ Vorwerk, Sunbeam, USA). TDC with no ingredients $(0 \%)$ was used as a control. After mixing, $200 \mathrm{~g}$ aliquots of the samples (control and samples with ingredients) were placed into glass jars and sealed (cold samples). The remaining products were heat-treated with continuous mixing $\left(80^{\circ} \mathrm{C}, 20 \mathrm{~min}\right)$, placed into glass jars (200 g aliquots) and sealed (hot samples). All samples (hot and cold) were stored at room temperature for $12 \mathrm{~h}$ before analysis. 


\section{Tomato products' characterization}

\section{Macroscopic properties}

Moisture content (MC, \% g water/100 g product) of tomato products was determined by weight loss by drying in a forced-air oven (ISCO NSV 9035, ISCO, Milan, Italy) at $80{ }^{\circ} \mathrm{C}$ to constant weight. At least triplicate tomato products samples were analyzed.

Water activity of tomato products were measured at $25^{\circ} \mathrm{C}$ (Aqualab 4TE, Decagon Devices, Inc. WA, USA). Triplicate measurements were taken for each tomato product.

The $\mathrm{pH}$ was measured at $25{ }^{\circ} \mathrm{C}$ (JENWAY $3510 \mathrm{pH}$ meter, Bibby Scientific Ltd, Stone, Staff, UK). Triplicate measurements were obtained for each tomato product.

Color parameters $L^{*}$ (Lightness), $a^{*}$ (degree of redness) and $b^{*}$ (degree of yellowness) were measured with a Colorimeter (D65, $10^{\circ}$ position, standard observer, CIE, 1978; CM 2600d, Minolta Co., Osaka, Japan). At least twelve measurements were taken for each sample. The $a^{*} / \mathrm{b}^{*}$ ratio was computed to describe redness index [24, 25]. Differences of color between control (TDC with no ingredients) and samples with added ingredients were evaluated using the $\Delta E$ value [26].

\section{Mesoscopic properties}

Apparent viscosity was measured with an ARES Rheometer (TA Instruments, New Castle, DE, USA), using a Couette geometry (cup diameter: $34 \mathrm{~mm}$; bob diameter; $32 \mathrm{~mm}$; height: $33 \mathrm{~mm})$. In brief, tomato product $(8 \mathrm{~mL})$ was placed into the cup and subjected to a rate sweep test $\left(1-600 \mathrm{~s}^{-1}\right.$, $25{ }^{\circ} \mathrm{C}$, points for decade 10 ) to obtain shear stress $(\tau)$ and viscosity. Shear rate $\left(\gamma, \mathrm{s}^{-1}\right)$ and shear stress (Pa) were then fitted with a non-Newtonian model to extrapolate flow index $(n)$, and the consistency coefficient $(K)[18,27]$.

\section{Molecular properties}

Molecular properties of tomato-based products were assessed with ${ }^{1} \mathrm{H}$ NMR Relaxometry. A Low resolution $(20 \mathrm{MHz}){ }^{1} \mathrm{H}$ NMR spectrometer (the MiniSpec, Bruker Biospin, Milano, Italy) operating at $25.0 \pm 0.1{ }^{\circ} \mathrm{C}$ was used. About $4 \mathrm{~g}$ of tomato product $(10 \mathrm{~mm}$ high) were placed into a $10 \mathrm{~mm}$ (diameter) NMR tube and then sealed with Parafilm ${ }^{\circledR}$ to prevent moisture loss during the NMR experiment.

${ }^{1} \mathrm{H}$ FIDs were acquired using a single $90^{\circ}$ pulse, followed by a dwell time of $7 \mu \mathrm{s}$, a recycle delay of $5 \mathrm{~s}$ and a $0.5 \mathrm{~ms}$ acquisition window and 900 data points. The curves were fitted with a two components model [exponential and gaussian; Sigmaplot, v6, Systat Software Inc., USA]:

$f(t)=y 0+A \times \exp ^{\left(\frac{t}{T A}\right)}+B \times \exp ^{\left(\frac{t}{T B}\right)^{2}}$,

where $\mathrm{y} 0$ is the FID decay offset, A and B are the intensities of each relaxation component, TA and TB are the apparent relaxation times.

$\mathrm{T}_{2}$ relaxation time was measured with a Carr-Purcell-Meiboom-Gill (CPMG) pulse sequence with a recycle delay of $3 \mathrm{~s}\left(\geq 5{ }^{1} \mathrm{H} \mathrm{T}_{1}\right)$, an interpulse spacing of $0.04 \mathrm{~ms}$ and 26,000 data points. ${ }^{1} \mathrm{H} \mathrm{T}_{2}$ curves were analyzed as quasi-continuous distributions of relaxation times using an UPENWin software (Alma Mater Studiorum, Bologna, Italy). Default values for all UPEN settings parameters were used with the exception of the LoXtrap parameter that was set to 1 to avoid extrapolation of relaxation times shorter than the first experimental point. ${ }^{1} \mathrm{H} \mathrm{T}_{2} \mathrm{CPMG}$ relaxation decays were also fitted with a discrete exponential model (Sigmaplot, v.6, Systat Software Inc., USA).

The ${ }^{1} \mathrm{H}$ self-diffusion coefficient (D) was measured, at $25{ }^{\circ} \mathrm{C}$, with a pulsed-field gradient spin echo (PFGSE) pulse sequence and a $40 \%$ gradient. The instrument was calibrated with water at $25^{\circ} \mathrm{C}\left(D=2.29 \times 10^{-9} \mathrm{~m}^{2} / \mathrm{s}\right)$.

\section{Statistical analysis}

Multivariate analysis of variance (MANOVA) was used to determine the influence of the fixed factors (ingredients: X, F, salt, sugar; heat treatment: hot, cold) on the physico-chemical properties of tomato products. Two MANOVA were performed based on fixed factors at a significance level of $\alpha=0.05$. The first MANOVA was a four ways-ANOVA considering four factors ( $T$ thermal treatment (cold/hot); TA, texturing agents ( $\mathrm{X}$ and $\mathrm{F})$; salt and sugar] and the percentages of total variations were computed to underline the contribution of different ingredients and their interactions in the variance of each parameter. As for the second MANOVA (five ways-ANOVA), five factors $[T$ thermal treatment (cold/hot); potato fiber $(\mathrm{F})$ ( 0 and $1 \%, \mathrm{~g}$ ingredient/100 g tomato); xanthan (X) $(0$ and $1 \%, \mathrm{~g}$ ingredient $/ 100 \mathrm{~g}$ tomato); salt $(0,0.5$ and $1 \%$, $\mathrm{g}$ ingredient $/ 100 \mathrm{~g}$ tomato); and sugar: $(0,0.5$ and $1 \%, \mathrm{~g}$ ingredient $/ 100 \mathrm{~g}$ tomato)] were considered to underline the potential of $\mathrm{F}$ as substitute of $\mathrm{X}$ in modulating the physicochemical properties of salt and sugar containing TDC. Significant differences among the mean values were calculated using Duncan's test. All experimental data were statistically analyzed using SPSS version 19.0 (SPSS Inc., Chicago, IL, USA). 


\section{Results and discussion}

Current international guidelines recommended salt/sugar intake reduction due to health concerns related to their overconsumption [29, 30]. Salt has been related to hypertension, cardiovascular diseases and stroke [31], while sugar is related to overweight, diabetes and cardiovascular diseases [32]. Therefore, the maximum level used in the present work was $1 \%$ (sugar or/and salt) versus higher amounts commonly used at an industrial level [3-4\% (salt); 4-8\% (sugar)] [12, 33]. The formulated products were also subjected to thermal treatment to simulate the industrial processing.

\section{Macroscopic properties}

As illustrated in Table 1, moisture content (MC) of TDC was significantly controlled by heat treatment $(\sim 31 \%)$ which induced a slight reduction in MC. Regarding stabilizing ingredients, the effect of sugar $(\sim 20 \%)$ was more pronounced followed by salt $(\sim 16 \%)$ and texturing agents $(\sim 6 \%)$. In particular, F, salt and sugar slightly reduced MC, whereas $\mathrm{X}$ did not show any significant effect. Water activity showed small differences among the studied formulations (0.948-0.958, Table 2). These changes resulted mainly from salt addition ( $\sim 73 \%$; Table 1$)$. Indeed, $a_{\mathrm{w}}$ was significantly reduced through the addition of salt alone or in conjunction with sugar. However, $T, \mathrm{X}$ and $\mathrm{F}$ and sugar addition did not significantly affect this parameter. The values of $\mathrm{pH}$ ranged from 4.102 to 4.229 (Table 2). Although the changes in the $\mathrm{pH}$ of TDC was minimal, they were mainly controlled by sugar $(\sim 84 \%)$. In fact, sugar addition significantly reduced the $\mathrm{pH}$ from $4.229(0 \%)$ to $4.102(1 \%)$. Heating minimally increased $\mathrm{pH}$ values [from $4.182(0 \%)$ to $4.195(1 \%)$ ]. Likewise, $\mathrm{F}$ addition slightly increased $\mathrm{pH}$ (from 4.183 to 4.200 ); while $\mathrm{X}$ and salt did not show a significant effect.

Table 1 Multivariate analysis based on Pillai's Trace test of the quality characteristics of tomato double concentrate with different formulation

\begin{tabular}{|c|c|c|c|c|c|c|c|c|c|c|c|c|}
\hline & & $T$ & TA & Salt & Sugar & $T \times \mathrm{TA}$ & $T \times$ salt & $T \times$ sugar & $\mathrm{TA} \times$ salt & TA $\times$ sugar & $T \times \mathrm{TA} \times$ salt & $T \times \mathrm{TA} \times$ sugar \\
\hline \multirow[t]{2}{*}{$\mathrm{MC}$} & Sig & $* * *$ & $* *$ & $* *$ & $* *$ & ns & ns & ns & ns & ns & $* *$ & $*$ \\
\hline & $\mathrm{SS} \%$ & 30.72 & 6.22 & 15.85 & 20.26 & 2.39 & 1.15 & 0.72 & 0.86 & 1.12 & 12.29 & 8.42 \\
\hline \multirow[t]{2}{*}{$a_{\mathrm{w}}$} & Sig & $\mathrm{ns}$ & $*$ & $*$ & ns & $*$ & $\mathrm{~ns}$ & $*$ & $*$ & $*$ & $*$ & $*$ \\
\hline & $\mathrm{SS} \%$ & 4.92 & 2.67 & 72.99 & 0.11 & 2.02 & 0.39 & 3.41 & 1.97 & 6.7 & 1.15 & 3.66 \\
\hline \multirow[t]{2}{*}{$\mathrm{pH}$} & Sig & $* *$ & $*$ & $\mathrm{~ns}$ & $* *$ & ns & $* *$ & $* *$ & $* *$ & $* *$ & $* *$ & $\mathrm{~ns}$ \\
\hline & $\mathrm{SS} \%$ & 0.96 & 0.67 & 0 & 83.65 & 0.13 & 0.89 & 1.25 & 4.59 & 5.99 & 1.84 & 0.04 \\
\hline \multirow[t]{2}{*}{$L^{*}$} & Sig & $* * *$ & $* * *$ & $* * *$ & $* * *$ & $* * *$ & $* * *$ & $* * *$ & $* * *$ & $* * *$ & $\mathrm{~ns}$ & $* *$ \\
\hline & $\mathrm{SS} \%$ & 46.22 & 10.83 & 3.22 & 12.4 & 3.45 & 4.57 & 0.62 & 3.59 & 8.93 & 0.02 & 6.14 \\
\hline \multirow[t]{2}{*}{$a^{*}$} & Sig & $* * *$ & $* * *$ & $* * *$ & $* * *$ & $* * *$ & $* * *$ & ns & $* *$ & $* *$ & ns & $* *$ \\
\hline & $\mathrm{SS} \%$ & 22.4 & 14.39 & 0.26 & 2.54 & 3.43 & 7.07 & 0 & 10.62 & 21.41 & 0.05 & 17.82 \\
\hline \multirow[t]{2}{*}{$b^{*}$} & Sig & $\mathrm{ns}$ & $* *$ & $* *$ & ns & $* *$ & $* *$ & ns & $* * *$ & $* * *$ & $*$ & $*$ \\
\hline & $\mathrm{SS} \%$ & 0 & 4.57 & 2.13 & 0.03 & 7.14 & 9.24 & 0.01 & 19.79 & 39.47 & 0.78 & 16.86 \\
\hline \multirow[t]{2}{*}{$a^{*} / b^{*}$} & Sig & $* *$ & ns & $*$ & $*$ & $*$ & $*$ & $*$ & $* *$ & $* * *$ & $\mathrm{~ns}$ & $* *$ \\
\hline & $\mathrm{SS} \%$ & 14.93 & 0.12 & 4.81 & 2.05 & 5.23 & 7.76 & 0.3 & 17.35 & 34.9 & 0.04 & 12.51 \\
\hline \multirow[t]{2}{*}{$\Delta E$} & Sig & $* * *$ & $* * *$ & $* * *$ & $* * *$ & $\mathrm{~ns}$ & $* *$ & $*$ & $* *$ & $* *$ & $* *$ & $* *$ \\
\hline & $\mathrm{SS} \%$ & 5.67 & 7.33 & 5.51 & 2.22 & 0.08 & 8.57 & 0.41 & 15.69 & 23.55 & 1.62 & 29.34 \\
\hline \multirow[t]{2}{*}{ K } & Sig & $* * *$ & $* * *$ & $* * *$ & $* * *$ & $* * *$ & $* * *$ & $* * *$ & $* * *$ & $* * *$ & $* * *$ & $* * *$ \\
\hline & $\mathrm{SS} \%$ & 5.59 & 66.84 & 2 & 4.5 & 2.95 & 1.33 & 0.38 & 2.01 & 2.57 & 4.62 & 7.22 \\
\hline \multirow[t]{2}{*}{$n$} & Sig & $* * *$ & $* * *$ & $* * *$ & $* * *$ & $* * *$ & $\mathrm{~ns}$ & $*$ & $* * *$ & $* * *$ & $* * *$ & $* * *$ \\
\hline & $\mathrm{SS} \%$ & 2.62 & 62.05 & 2.65 & 3.58 & 4.96 & 0.27 & 0.46 & 7.57 & 5.89 & 4.21 & 5.73 \\
\hline \multirow[t]{2}{*}{ Pop A } & Sig & $*$ & $* * *$ & ns & $*$ & $*$ & ns & $*$ & $*$ & $\mathrm{~ns}$ & $\mathrm{~ns}$ & $\mathrm{~ns}$ \\
\hline & $\mathrm{SS} \%$ & 1.75 & 89 & 0.37 & 1.12 & 1.57 & 0.08 & 2.43 & 1.58 & 0.06 & 0.68 & 1.37 \\
\hline \multirow[t]{2}{*}{$\mathrm{TA}$} & Sig & $* *$ & $* *$ & $*$ & $\mathrm{~ns}$ & $*$ & $*$ & $\mathrm{~ns}$ & $*$ & ns & $*$ & $*$ \\
\hline & $\mathrm{SS} \%$ & 5.44 & 67.01 & 0.95 & 1.16 & 3.79 & 5.77 & 0.28 & 2.6 & 0.58 & 9.43 & 2.98 \\
\hline \multirow[t]{2}{*}{$D$} & Sig & $* * *$ & $* * *$ & $* * *$ & $* * *$ & $* * *$ & $* * *$ & ns & ns & $\mathrm{ns}$ & ns & $*$ \\
\hline & $\mathrm{SS} \%$ & 34 & 22.18 & 8.29 & 29.96 & 0.39 & 1.71 & 0.01 & 0.04 & 0.08 & 0.07 & 3.26 \\
\hline
\end{tabular}

$n s$ not significant, $S S$ sum of squares

$* p \leq 0.05$

$* * p \leq 0.01$

$* * * p \leq 0.001$ 


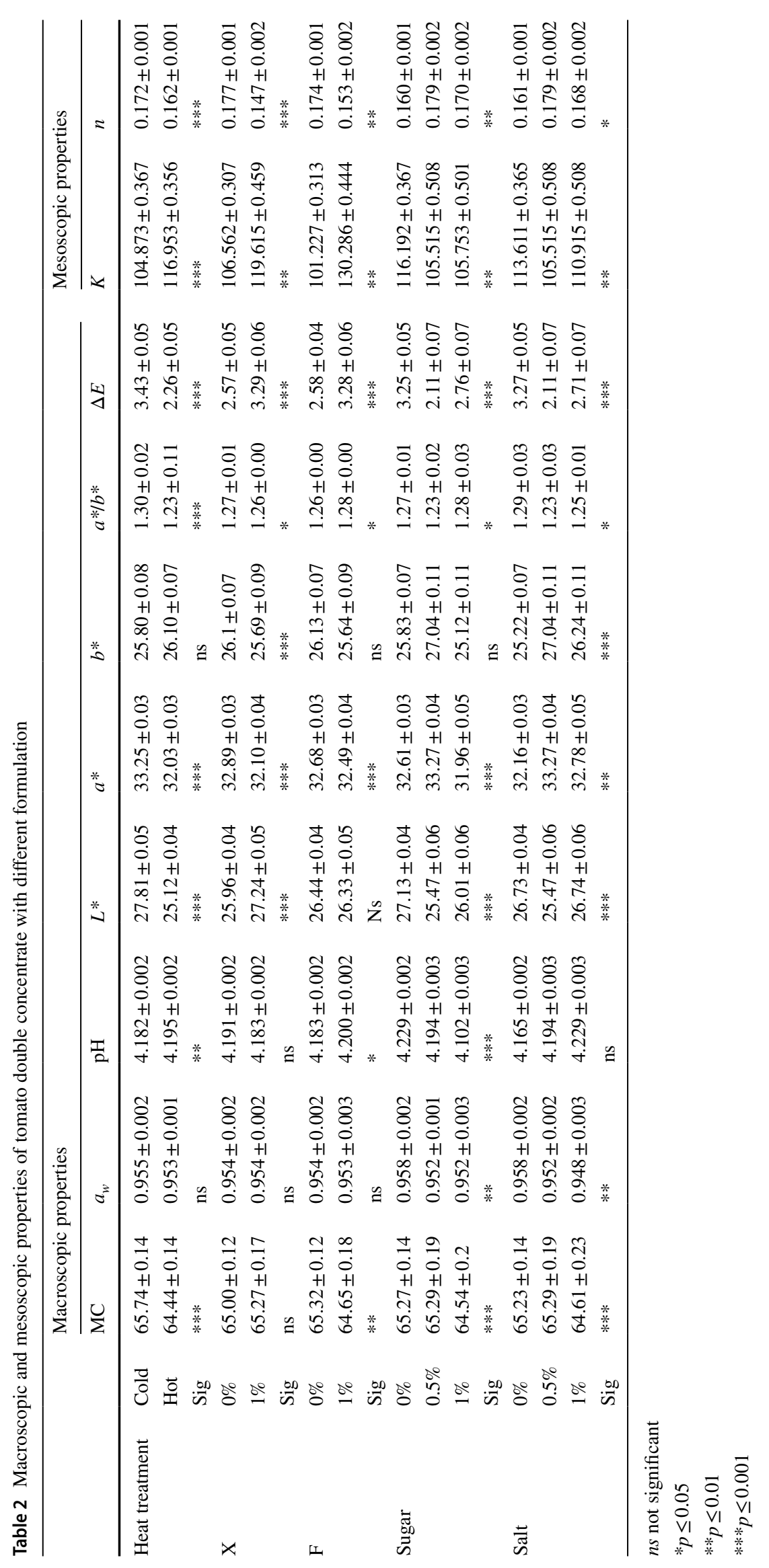


Color has been characterized considering $L^{*}, a^{*}, b^{*}$, $a * / b^{*}$ and $\Delta E$. The effect of fixed factors ( $T$, TA, sugar and salt) on the color of tomato products is summarized in Table 1. The main results of MANOVA revealed that: $L^{*}$ was mainly controlled by $T(\sim 46 \%)$ and sugar $(\sim 12 \%)$; $a^{*}$ was controlled by $T(\sim 22 \%)$, TA $\times$ sugar $(\sim 21 \%)$, $T \times$ TA $\times$ sugar $(\sim 18 \%)$, TA $(\sim 14 \%)$, TA $\times$ salt $(\sim 11 \%) ; b^{*}$ was controlled by TA $\times$ sugar $(\sim 39 \%)$, TA $\times$ salt $(\sim 20 \%)$; $T \times$ TA $\times$ sugar $(\sim 17 \%) . T$ significantly reduced $L^{*}$ and $a^{*}$, likely due to the formation of dark compounds by non-enzymatic browning, $L^{*}$ was increased by $\mathrm{X}$ and decreased by sugar addition, but it was not affected by F. When singly added, salt did not show any effect on $L^{*}$, but when added with sugar, it significantly reduced $L^{*}$. Moreover, $a^{*}$ was significantly decreased by both $\mathrm{X}$ and $\mathrm{F}$. However, it was increased after the addition of sugar. Interestingly, when salt was included in TDC formulation by itself, no significant changes were observed, whereas, in conjunction with sugar, $a^{*}$ significantly increased. As for $b^{*}, T$, sugar and $\mathrm{F}$ did not show significant effects, only $\mathrm{X}$ addition induced a significant decrease. Salt increased $b^{*}$ by itself [from $25.22(0 \%)$ to $26.44(1 \%)$ ], and even more in conjunction with sugar (27.04). The redness index $\left(a^{*} / b^{*}\right.$ ratio) for unprocessed TDC was the highest (1.3), but when subjected to heat treatment, this value was significantly reduced (1.23). This result might be due to carotenoids degradation, in particular, the isomerization and oxidation lycopene [34,35], although no specific quantification was carried out in this work. However, the texturizing ingredients minimally changed $a^{*} / b^{*}$ ratio; in particular, a slight increase was caused after $\mathrm{X}$ and $F$ inclusion in the formulation of TDC. $\Delta E$ is used to determine whether the total color difference of a sample was visually observable, as compared to the standard sample. Table 2 showed that $\Delta \mathrm{E}$ decreased by $T$ as well as salt and sugar (together or separately), while TA increased $\Delta E$ values to be slightly higher than 3 indicating an important change in color in agreement with previous findings [19, 36].

\section{Mesoscopic properties}

Consistency coefficient and flow behavior index were calculated and reported in Table 2. The flow behavior index (n) was lower than 1 in all samples indicating a pseudoplastic behavior. The influence of processing on the consistency coefficient $(K)$ and the flow index $(n)$ was weak $(\sim 6 \%$ and $\sim 3 \%$, respectively; Table 1 ), where heating resulted in $K$ increase and $n$ decrease (Table 2). This result can be likely attributed to total solids content increase $[9,12,37]$. MANOVA results (Table 1) underlined that $K$ and $n$ were chiefly controlled by TA ( $\sim 67 \%$ and $\sim 62 \%$, respectively), while sugar and salt were less relevant $(\sim 2-4.5 \%)$. Overall, the addition of salt or sugar induced a reduction of $K$ and no particular change in $n$. As for the interactions between TA, salt and sugar, their contribution in the variability of the mesoscopic properties was in most cases lower than $7 \%$. Due to the importance of TA in modulating the rheological properties (as shown in Table 1), $\mathrm{X}$ and $\mathrm{F}$ were considered 2 factors rather than 1 in a second MANOVA. The results (data not shown) underlined that $\mathrm{F}$ was more efficient in increasing $K$ and $n$ than $\mathrm{X}$ consistently with our previous work [18]. Table 3 summarized the changes in $K$ and $n$ as a function of the texturing agent ( $\mathrm{X}$ and $\mathrm{F}$ ) in association with salt and sugar. Overall, increasing hydrocolloid concentration increased $K$ and decreased $n$ due to hydrocolloids ability to trap water and to create a gel-like network [38]. This result is in concordance with several previous works $[12,13,15$,
Table 3 Consistency coefficient $(K)$ and flow behavior index $(n)$ of tomato double concentrate with different formulation

\begin{tabular}{clclcc}
\hline TA & Sugar/salt & F $\times$ salt & X $\times$ salt & F $\times$ sugar & X $\times$ sugar \\
\hline$K$ & & & & \\
$0 \%$ & $0 \%$ & $103.82 \pm 0.45 \mathrm{~b} / \mathrm{A}$ & $110.98 \pm 0.44 \mathrm{~b} / \mathrm{B}$ & $105.01 \pm 0.45 \mathrm{~b} / \mathrm{A}$ & $114.8 \pm 0.44 \mathrm{~b} / \mathrm{B}$ \\
& $0.5 \%$ & $98.64 \pm 0.61 \mathrm{a} / \mathrm{A}$ & $97.31 \pm 0.61 \mathrm{a} / \mathrm{A}$ & $98.64 \pm 0.61 \mathrm{ab} / \mathrm{A}$ & $97.31 \pm 0.61 \mathrm{a} / \mathrm{A}$ \\
& $1 \%$ & $98.63 \pm 0.63 \mathrm{a} / \mathrm{A}$ & $106.99 \pm 0.61 \mathrm{ab} / \mathrm{B}$ & $96.25 \pm 0.62 \mathrm{a} / \mathrm{A}$ & $99.33 \pm 0.59 \mathrm{a} / \mathrm{AB}$ \\
$1 \%$ & $0 \%$ & $133.2 \pm 0.63 \mathrm{~b} / \mathrm{B}$ & $118.89 \pm 0.65 \mathrm{a} / \mathrm{A}$ & $133.56 \pm 0.63 \mathrm{~b} / \mathrm{B}$ & $118.97 \pm 0.65 \mathrm{a} / \mathrm{A}$ \\
& $0.5 \%$ & $119.27 \pm 0.92 \mathrm{a} / \mathrm{A}$ & $121.92 \pm 0.92 \mathrm{~b} / \mathrm{A}$ & $119.27 \pm 0.92 \mathrm{a} / \mathrm{A}$ & $121.92 \pm 0.92 \mathrm{~b} / \mathrm{A}$ \\
& $1 \%$ & $135.47 \pm 0.86 \mathrm{c} / \mathrm{B}$ & $118.77 \pm 0.92 \mathrm{a} / \mathrm{A}$ & $124.75 \pm 0.86 \mathrm{ab} / \mathrm{B}$ & $118.6 \pm 0.92 \mathrm{a} / \mathrm{A}$ \\
$N$ & & & & \\
$0 \%$ & $0 \%$ & $0.166 \pm 0.002 \mathrm{a} / \mathrm{A}$ & $0.169 \pm 0.002 \mathrm{a} / \mathrm{A}$ & $0.166 \pm 0.002 \mathrm{a} / \mathrm{A}$ & $0.167 \pm 0.002 \mathrm{a} / \mathrm{A}$ \\
& $0.5 \%$ & $0.186 \pm 0.002 \mathrm{~b} / \mathrm{A}$ & $0.191 \pm 0.002 \mathrm{bc} / \mathrm{A}$ & $0.186 \pm 0.002 \mathrm{~b} / \mathrm{A}$ & $0.191 \pm 0.002 \mathrm{abA}$ \\
& $1 \%$ & $0.180 \pm 0.002 \mathrm{~b} / \mathrm{A}$ & $0.179 \pm 0.002 \mathrm{~b} / \mathrm{A}$ & $0.178 \pm 0.002 \mathrm{ab} / \mathrm{A}$ & $0.183 \pm 0.002 \mathrm{ab} / \mathrm{A}$ \\
$1 \%$ & $0 \%$ & $0.152 \pm 0.002 \mathrm{ab} / \mathrm{A}$ & $0.145 \pm 0.003 \mathrm{a} / \mathrm{A}$ & $0.147 \pm 0.002 \mathrm{a} / \mathrm{A}$ & $0.145 \pm 0.003 \mathrm{a} / \mathrm{A}$ \\
& $0.5 \%$ & $0.163 \pm 0.004 \mathrm{~b} / \mathrm{A}$ & $0.154 \pm 0.004 \mathrm{~b} / \mathrm{A}$ & $0.163 \pm 0.004 \mathrm{ab} / \mathrm{A}$ & $0.154 \pm 0.004 \mathrm{ab} / \mathrm{A}$ \\
& $1 \%$ & $0.144 \pm 0.003 \mathrm{a} / \mathrm{A}$ & $0.145 \pm 0.004 \mathrm{a} / \mathrm{A}$ & $0.155 \pm 0.003 \mathrm{ab} / \mathrm{A}$ & $0.144 \pm 0.004 \mathrm{a} / \mathrm{A}$ \\
\hline
\end{tabular}

$T A$ texturing agent $(\mathrm{F}$ and $\mathrm{X})$; consistency coefficient $(K)$ and the flow index $(n), F$ potato fiber, $X$ xanthan gum 
$18,19]$. In particular, $F$ enabled an important enhancement of $K$ over X [130 (1\% F) versus $119(1 \% \mathrm{X})]$, which can be attributed to higher affinity of $\mathrm{F}$ for binding water molecules. Furthermore, the formulation including $1 \% \mathrm{~F}$ and $1 \%$ salt enabled the highest $K$ value. However, $n$ increased when salt $(0.5 \%)$ and sugar $(0.5 \%)$ were added; but if $1 \%$ of sugar or salt were used, a reduction in $n$ was observed.

\section{Molecular properties}

Molecular characterization of TDC formulations was performed to enable a deep understanding of the effects of ingredients and heating at a molecular level using the Low resolution ${ }^{1} \mathrm{H}$ NMR $(20 \mathrm{MHz})$ technique.

Free Induction Decay ( ${ }^{1} \mathrm{H}$ FID) enabled the determination of two proton populations $A$ and $B$ characterized by their relative abundance (pop A, pop B) and relaxation times $\mathrm{T}_{\mathrm{A}}$ and $T_{B}$. Based on MANOVA results (Table1), pop A and $\mathrm{T}_{\mathrm{A}}$ were mainly controlled by the TA ( 89 and $67 \%$, respectively), whereas $T$, salt and sugar were less relevant. The more rigid protons population (pop A) was represented by $\sim 6 \%$ of protons and it relaxed at $\sim 0.01 \mathrm{~ms}$. More specifically, Pop A was increased by F but reduced by X (Table 4). Pop A generally reflected the presence of more solids in all products (increasing pop A with increasing amount of added ingredients) [18]. Subsequently, this result can suggest that F reduced proton mobility through the formation of a rigid binding with water resulting in higher consistency as mentioned above. As well, heating induced an increase of pop A. Sugar, however, did not have a significant effect, while salt significantly reduced pop $\mathrm{A}$. As for $\mathrm{T}_{\mathrm{A}}$, a slight increase was found after $\mathrm{X}$ addition contrary to $\mathrm{F}$, while both sugar and salt did not show any significant effect. Pop B was not considered because it overlaps with the times of pop C.

The identified populations in the ${ }^{1} \mathrm{H} \mathrm{T}_{2}$ experimental window were population C (pop C), population D (pop D) and population E (pop E). These populations were characterized by their average relaxation times $\left(T_{2 \mathrm{C}}, T_{2 \mathrm{D}}\right.$ and $T_{2 \mathrm{E}}$, respectively) and protons abundances (pop C, pop D, pop E). An additional population $\mathrm{F}$ (pop $\mathrm{F}$ ) was exclusively found in X-based products at relaxation time $\mathrm{T}_{2 \mathrm{~F}} \cdot{ }^{1} \mathrm{H} \mathrm{T}_{2}$ populations and relaxation times are reported in Table 4. Statistically, all four identified populations and their relaxations times were mainly controlled by TA and slightly by $T$, as shown in Table 5. Interestingly, ${ }^{1} \mathrm{H} \mathrm{T}_{2}$ proton mobility was not affected by salt or sugar, probably because the amounts were quite low to induce relevant changes on proton dynamics. In contrast, the presence of salt was found relevant in molecular changes when $6 \%$ of salt was included in tomato products [12]. The less mobile populations, pop C and pop $\mathrm{D}$, and their corresponding relaxation times were significantly increased by F but reduced by X. As well, they were significantly decreased by heating, which might be due to structural changes (i.e. consistency coefficient $K$ and Bostwick consistency) [19]. However, the more mobile population, pop E, was significantly increased by $\mathrm{X}$, but reduced by F. Heating also induced an increase in pop $\mathrm{E}$ but it reduced its relaxation time. These changes in protons mobility might suggest occurrence of an interactions between each specific sauce ingredient and water that might have resulted in the development of a molecular structure with lower mobility [19]. For fresh tomato, the attribution of ${ }^{1} \mathrm{H} \mathrm{T}_{2}$ in relation to cell compartmentalization was as follows: exchangeable solutes $(<100 \mathrm{~ms})$, cell walls $(\approx 100 \mathrm{~ms})$, cytoplasm (400-600 ms) and vacuole (900-1600 ms) protons [39]. However, the results reported in Table 4 showed different proton mobility that can be attributed to tomato processing causing the destruction of cell wall compartmentalization and tissues structure. Furthermore, the inclusion of different ingredients resulted in different proton exchange in concordance with previous works $[12,19]$. Noteworthy, the inclusion of $\mathrm{X}$ in the formulation enabled the detection of a fourth population (pop F), which is the most mobile population with a corresponding relaxation time $\left(T_{2 \mathrm{~F}}\right) \approx 193$ to $412 \mathrm{~ms}$. Therefore, $\mathrm{X}$ induced the increase of the most mobile populations (pop E and pop F), while F induced the increase of the most rigid populations (pop C and pop D), in agreement with the mesoscopic findings.

Proton self-diffusion coefficients $\left({ }^{1} \mathrm{H}\right.$ D) was significantly influenced by $T(\approx 34 \%)$, sugar $(\approx 30 \%)$, TA $(\approx 22 \%)$ and salt $(\approx 8 \%)$ (Table 1$)$. D values were decreased by heating [from $1.048 \pm 0.001$ (cold) to $1.019 \pm 0.004 * 10^{-9} \mathrm{~m}^{2} / \mathrm{s}$ (hot)], sugar [from $1.044 \pm 0.001 * 10^{-9} \mathrm{~m}^{2} / \mathrm{s}(0 \%) ; 1.028 \pm 0.001 * 10^{-9} \mathrm{~m}^{2} / \mathrm{s}$ $\left.(0.5 \%) ; 1.018 \pm 0.001 * 10^{-9} \mathrm{~m}^{2} / \mathrm{s}(1 \%)\right], \mathrm{X}$ [from $1.041 \pm 0.001(0 \%)$ to $\left.1.019 \pm 0.001 * 10^{-9} \mathrm{~m}^{2} / \mathrm{s}(1 \%)\right]$ and slightly by salt addition. These results can be due to adding salt/sugar or to the formation of a viscous gel matrix (X) at a molecular level. However, F addition did not affect protons translational mobility contrarily to our previous work [18]. This can be attributed to more pronounced impact of sugar or salt masking F impact on D.

\section{Conclusion}

The effect of heating and addition of ingredients (X, F, salt and sugar) on TDC properties was studied from a multilevel perspective [macroscopic (water activity, $\mathrm{pH}$ and color); mesoscopic (rheological attributes); and molecular (proton mobility)]. Based on multivariate statistics, water activity and moisture content merely varied, where these small changes were mostly controlled by $T$ (reduction of moisture content), salt (reduction of water activity) and sugar (increase of $\mathrm{pH}$ ). Color properties were more controlled by heating, texturing agents and their interactions with sugar/ 


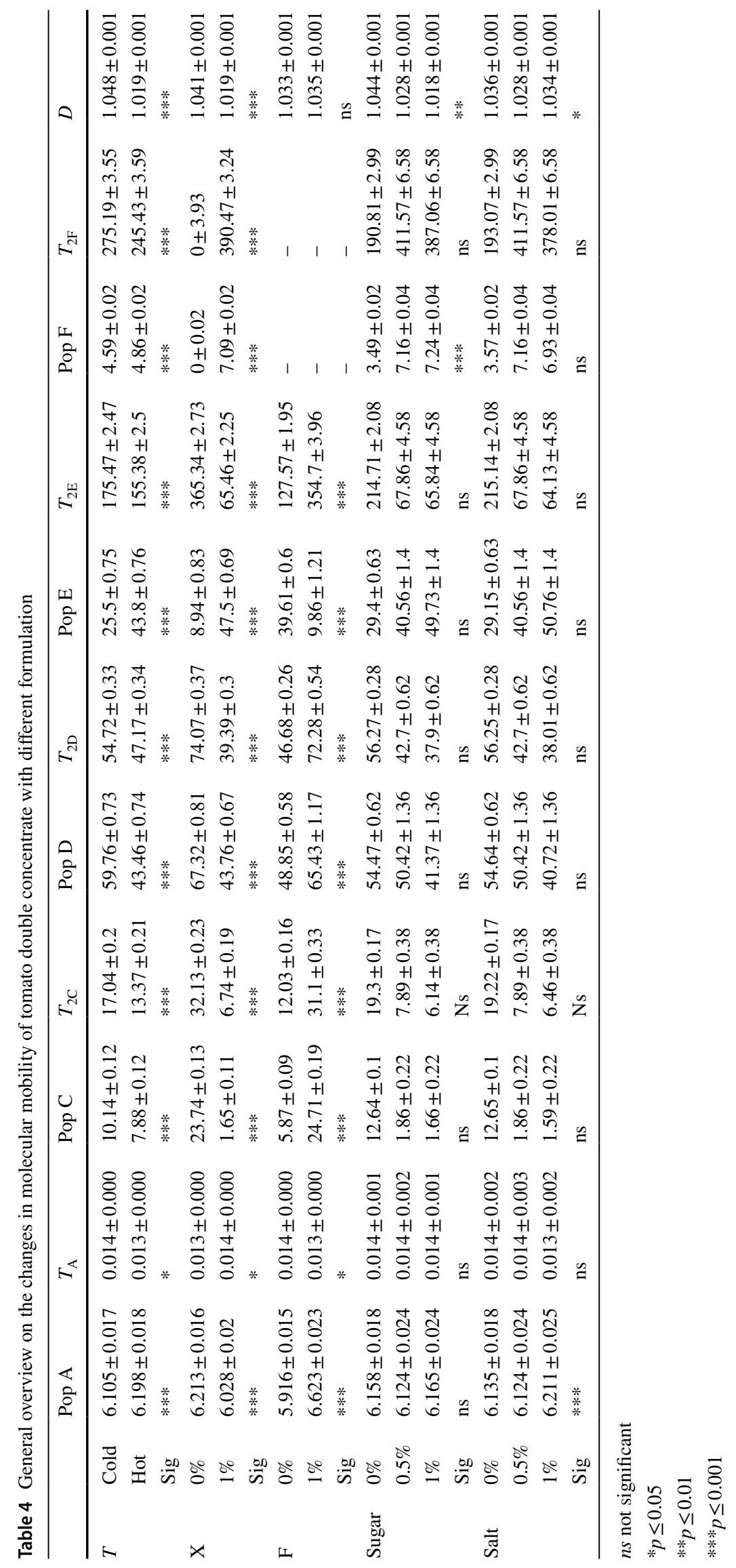


Table 5 Multivariate analysis based on Pillai's trace test of ${ }^{1} \mathrm{H} \mathrm{T}_{2}$ relaxation times and populations of tomato double concentrate with different formulations

\begin{tabular}{|c|c|c|c|c|c|c|c|c|}
\hline & \multicolumn{2}{|c|}{ Pop C } & \multicolumn{2}{|l|}{$T_{2 \mathrm{C}}$} & \multicolumn{2}{|c|}{ Pop D } & \multicolumn{2}{|l|}{$T_{2 \mathrm{D}}$} \\
\hline & Sig & SS\% & Sig & SS $\%$ & Sig & $\mathrm{SS} \%$ & Sig & SS $\%$ \\
\hline$T$ & $*$ & 1.70 & $*$ & 2.77 & $* * *$ & 24.16 & $*$ & 5.56 \\
\hline TA & $* * *$ & 94.58 & $* * *$ & 96.85 & $* * *$ & 50.01 & $* * *$ & 93.73 \\
\hline Salt & ns & 0.00 & $\mathrm{~ns}$ & 0.00 & $\mathrm{~ns}$ & 0.17 & ns & 0.04 \\
\hline Sugar & ns & 0.00 & $\mathrm{~ns}$ & 0.01 & ns & 0.07 & ns & 0.05 \\
\hline$T \times \mathrm{TA}$ & $*$ & 3.69 & ns & 0.04 & $* * *$ & 20.56 & ns & 0.32 \\
\hline$T \times$ Salt & ns & 0.01 & $\mathrm{~ns}$ & 0.28 & $*$ & 1.65 & ns & 0.21 \\
\hline \multirow[t]{3}{*}{$T \times$ sugar } & ns & 0.00 & $\mathrm{~ns}$ & 0.05 & $*$ & 3.38 & ns & 0.09 \\
\hline & \multicolumn{2}{|c|}{ Pop E } & \multicolumn{2}{|l|}{$T_{2 \mathrm{E}}$} & \multicolumn{2}{|c|}{ Pop F } & \multicolumn{2}{|l|}{$T_{2 \mathrm{~F}}$} \\
\hline & Sig & SS $\%$ & Sig & SS $\%$ & Sig & SS\% & $\overline{\mathrm{Sig}}$ & SS\% \\
\hline$T$ & $* *$ & 18.04 & $*$ & 0.62 & $*$ & 0.20 & $*$ & 0.73 \\
\hline TA & $* * *$ & 71.56 & $* * *$ & 97.16 & $* * *$ & 99.65 & $* * *$ & 98.88 \\
\hline Salt & ns & 0.09 & ns & 0.00 & ns & 0.01 & ns & 0.02 \\
\hline Sugar & $\mathrm{ns}$ & 0.02 & $\mathrm{~ns}$ & 0.00 & ns & 0.06 & ns & 0.00 \\
\hline$T \times \mathrm{TA}$ & $* *$ & 7.35 & $*$ & 2.21 & ns & 0.05 & ns & 0.25 \\
\hline$T \times$ Salt & $*$ & 0.96 & ns & 0.00 & ns & 0.02 & ns & 0.01 \\
\hline$T \times$ sugar & $*$ & 1.98 & $\mathrm{~ns}$ & 0.00 & ns & 0.00 & $\mathrm{~ns}$ & 0.12 \\
\hline
\end{tabular}

$n s$ not significant, $S S$ sum of squares

$* p \leq 0.05$

$* * p \leq 0.01$

$* * * p \leq 0.001$

salt. Indeed, color change $(\Delta E)$ was increased by $\mathrm{X}$ and $\mathrm{F}$ addition, while it was reduced by heating and the addition of salt and sugar. Mesoscopic properties were mainly controlled by texturing agents, where consistency coefficient $(K)$ was improved (increased) by F over X. Likewise, water status at molecular level chiefly influenced by TA. In particular, $\mathrm{F}$ addition resulted in the increase of the rigid populations abundance and consistency, while $\mathrm{X}$ increased the more mobile populations abundance. These results suggested that the addition of texturing ingredients had more ability to modulate the consistency and proton mobility over salt and sugar.

Funding Open access funding provided by Università degli Studi di Parma within the CRUI-CARE Agreement.

\section{Declarations}

Conflict of interest The authors declare that they have no confict of interest.

Ethical approval This article does not contain any studies with human or animal subjects.
Open Access This article is licensed under a Creative Commons Attribution 4.0 International License, which permits use, sharing, adaptation, distribution and reproduction in any medium or format, as long as you give appropriate credit to the original author(s) and the source, provide a link to the Creative Commons licence, and indicate if changes were made. The images or other third party material in this article are included in the article's Creative Commons licence, unless indicated otherwise in a credit line to the material. If material is not included in the article's Creative Commons licence and your intended use is not permitted by statutory regulation or exceeds the permitted use, you will need to obtain permission directly from the copyright holder. To view a copy of this licence, visit http://creativecommons.org/licenses/by/4.0/.

\section{References}

1. Li N, Feng Z, Niu Y, Yu L (2018) Structural, rheological and functional properties of modified soluble dietary fiber from tomato peels. Food Hydrocoll 77:557-565. https://doi.org/10.1016/J. FOODHYD.2017.10.034

2. Namir M, Suleiman AR, Hassanien MFR (2015) Characterization and functionality of alcohol insoluble solids from tomato pomace as fat substitute in low fat cake. J Food Meas Charact 9:557-563. https://doi.org/10.1007/s11694-015-9264-1

3. Niu Y, Li N, Xia Q et al (2018) Comparisons of three modifications on structural, rheological and functional properties of soluble dietary fibers from tomato peels. LWT 88:56-63. https://doi. org/10.1016/j.lwt.2017.10.003 
4. Wang Y, Sun P, Li H et al (2018) Rheological behavior of tomato fiber suspensions produced by high shear and high pressure homogenization and their application in tomato products. Int $\mathrm{J}$ Anal Chem 2018:1-12. https://doi.org/10.1155/2018/5081938

5. Jiang F, Hsieh Y-L (2015) Cellulose nanocrystal isolation from tomato peels and assembled nanofibers. Carbohydr Polym 122:60-68. https://doi.org/10.1016/j.carbpol.2014.12.064

6. Motamedzadegan A, Tabarestani HS (2011) Tomato processing, quality, and nutrition. In: Sinha NK (ed) Handbook of vegetables and vegetable processing. Wiley-Blackwell, Oxford, pp 739-757

7. Barrett DM, Anthon GE (2008) Color quality of tomato products. American Chemical Society, US, pp 131-139

8. Plaza L, Muñoz M, de Ancos B, Cano MP (2003) Effect of combined treatments of high-pressure, citric acid and sodium chloride on quality parameters of tomato puree. Eur Food Res Technol 216:514-519. https://doi.org/10.1007/s00217-003-0689-0

9. Torbica A, Belović M, Mastilović J et al (2016) Nutritional, rheological, and sensory evaluation of tomato ketchup with increased content of natural fibres made from fresh tomato pomace. Food Bioprod Process 98:299-309. https://doi.org/10.1016/j.fbp.2016. 02.007

10. Tibäck E, Langton M, Oliveira J, Ahrné L (2014) Mathematical modeling of the viscosity of tomato, broccoli and carrot purees under dynamic conditions. J Food Eng 124:35-42. https://doi.org/ 10.1016/j.jfoodeng.2013.09.031

11. Bayod E, Willers EP, Tornberg E (2008) Rheological and structural characterization of tomato paste and its influence on the quality of ketchup. LWT - Food Sci Technol 41:1289-1300. https:// doi.org/10.1016/j.lwt.2007.08.011

12. Carini E, Curti E, Mora B et al (2015) Effect of flour, gelatin and salt on water status of tomato sauce. Food Biophys 10:129-133. https://doi.org/10.1007/s11483-014-9369-9

13. Belović M, Pajić-Lijaković I, Torbica A et al (2016) The influence of concentration and temperature on the viscoelastic properties of tomato pomace dispersions. Food Hydrocoll 61:617-624. https:// doi.org/10.1016/j.foodhyd.2016.06.021

14. Niu Y, Xia Q, Gu M, Yu L (2019) Interpenetrating network gels composed of gelatin and soluble dietary fibers from tomato peels. Food Hydrocoll 89:95-99. https://doi.org/10.1016/j.foodhyd. 2018.10.028

15. Sahin H, Ozdemir F (2004) Effect of some hydrocolloids on the rheological properties of different formulated ketchups. Food Hydrocoll 18:1015-1022. https://doi.org/10.1016/J.FOODHYD. 2004.04.006

16. EU, (2008) Regulation (EC) No 1333/2008 regulation (EC) No 1333/2008 of the European Parliament and of the Council on food additives. OJL 26:19-27

17. Asioli D, Aschemann-Witzel J, Caputo V et al (2017) Making sense of the "clean label" trends: a review of consumer food choice behavior and discussion of industry implications. Food Res Int 99:58-71

18. Diantom A, Boukid F, Carini E et al (2020) Can potato fiber efficiently substitute xanthan gum in modulating chemical properties of tomato products? Food Hydrocoll 101:105508. https://doi.org/ 10.1016/j.foodhyd.2019.105508

19. Diantom A, Curti E, Carini E, Vittadini E (2017) Effect of added ingredients on water status and physico-chemical properties of tomato sauce. Food Chem 236:101-108. https://doi.org/10.1016/j. foodchem.2017.01.160

20. Dobrowolski P, Huet P, Karlsson P et al (2012) Potato fiber protects the small intestinal wall against the toxic influence of acrylamide. Nutrition 28:428-435. https://doi.org/10.1016/j.nut.2011. 10.002

21. Olatunde GO, Henshaw FO, Idowu MA, Tomlins K (2016) Quality attributes of sweet potato flour as influenced by variety, pretreatment and drying method. Food Sci Nutr 4:623-635. https:// doi.org/10.1002/fsn3.325
22. Dhingra D, Michael M, Rajput H, Patil RT (2012) Dietary fibre in foods: a review. J Food Sci Technol 49:255-266. https://doi.org/ 10.1007/s13197-011-0365-5

23. Lucera A, Costa C, Conte A, Del Nobile MA (2012) Food applications of natural antimicrobial compounds. Front Microbiol 3:287. https://doi.org/10.3389/fmicb.2012.00287

24. Barreiro JA, Milano M, Sandoval AJ (1997) Kinetics of colour change of double concentrated tomato paste during thermal treatment. J Food Eng 33:359-371. https://doi.org/10.1016/S02608774(97)00035-6

25. Batu A (2004) Determination of acceptable firmness and colour values of tomatoes. J Food Eng 61:471

26. Raj Pant D, Farup I (2012) Riemannian formulation and comparison of color difference formulas. Color Res Appl 37:429-440. https://doi.org/10.1002/col.20710

27. Campesi A, Cerri MO, Hokka CO, Badino AC (2009) Determination of the average shear rate in a stirred and aerated tank bioreactor. Bioprocess Biosyst Eng 32:241-248. https://doi.org/10.1007/ s00449-008-0242-4

28. Le Grand F, Cambert M, Mariette F (2007) NMR signal analysis to characterize solid, aqueous, and lipid phases in baked cakes. $\mathrm{J}$ Agric Food Chem 55:10947-10952. https://doi.org/10.1021/jf071 $735 \mathrm{r}$

29. MacGregor GA, Hashem KM (2014) Action on sugar-lessons from UK salt reduction programme. Lancet 383:929-931

30. Henney JE, Taylor CL, Boon CS (2010) Strategies to reduce sodium intake in the United States. National Academies Press (US)

31. Liem DG, Miremadi F, Keast RSJ (2011) Reducing sodium in foods: the effect on flavor. Nutrients 3:694-711. https://doi.org/ 10.3390/nu3060694

32. Clemens RA, Jones JM, Kern M et al (2016) Functionality of sugars in foods and health. Compr Rev Food Sci Food Saf 15:433470. https://doi.org/10.1111/1541-4337.12194

33. Rajoria A, Chauhan AK, Kumar J (2015) Studies on formulation of whey protein enriched concentrated tomato juice beverage. J Food Sci Technol 52:885-893. https://doi.org/10.1007/ s13197-013-1063-2

34. Jabbari S-S, Jafari SM, Dehnad D, Shahidi S-A (2018) Changes in lycopene content and quality of tomato juice during thermal processing by a nanofluid heating medium. J Food Eng 230:1-7. https://doi.org/10.1016/J.JFOODENG.2018.02.020

35. Singh P, Goyal GK (2008) Dietary lycopene: its properties and anticarcinogenic effects. Compr Rev Food Sci Food Saf 7:255270. https://doi.org/10.1111/j.1541-4337.2008.00044.x

36. Limbo S, Piergiovanni L (2006) Shelf life of minimally processed potatoes: part 1. Effects of high oxygen partial pressures in combination with ascorbic and citric acids on enzymatic browning. Postharvest Biol Technol 39:254-264. https://doi.org/10.1016/j. postharvbio.2005.10.016

37. Tibäck EA, Svelander CA, Colle IJP et al (2009) Mechanical and thermal pretreatments of crushed tomatoes: effects on consistency and in vitro accessibility of lycopene. J Food Sci 74:E386-E395. https://doi.org/10.1111/j.1750-3841.2009.01255.x

38. Saha D, Bhattacharya S (2010) Hydrocolloids as thickening and gelling agents in food: a critical review. J Food Sci Technol 47:587-597. https://doi.org/10.1007/s13197-010-0162-6

39. Musse M, Cambert M, Mariette F (2010) NMR study of water distribution inside tomato cells: effects of water stress. Appl Magn Reson 38:455-469. https://doi.org/10.1007/s00723-010-0139-7

Publisher's Note Springer Nature remains neutral with regard to jurisdictional claims in published maps and institutional affiliations. 